\title{
Combination phentermine and topiramate for weight maintenance: the first Australian experience
}

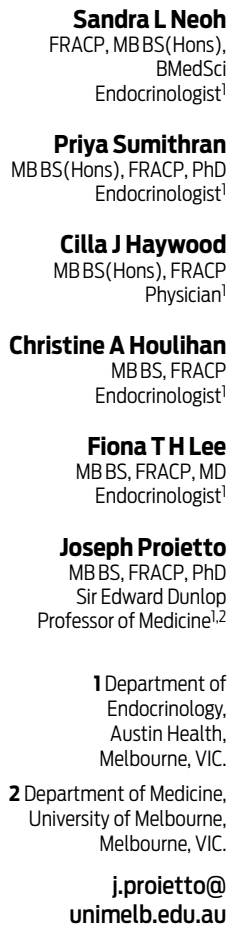

MJA 2014; 201: 224-226 doi: 10.5694/mjal3.00193

Editorial p 184

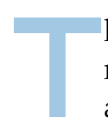
he global obesity epidemic has not spared Australia; $62.8 \%$ of adults were classified as obese or overweight in the 2011-12 financial year. ${ }^{1}$ While bariatric surgery is effective, access is poor for those most in need. ${ }^{2}$ Calorie restriction diets are successful in inducing weight loss, but weight is usually regained with time owing to hormonal adaptations that increase hunger, which occur in response to weight loss. ${ }^{3}$ There is a clear role for pharmacotherapy in appetite suppression for maintenance of weight loss.

The US Food and Drug Administration recently approved combination phentermine and controlled-release topiramate (in doses ranging from $3.75 \mathrm{mg}$ phentermine plus $23 \mathrm{mg}$ topiramate to $15 \mathrm{mg}$ phentermine plus $92 \mathrm{mg}$ topiramate) for use in adults with a body mass index $(\mathrm{BMI})>30 \mathrm{~kg} / \mathrm{m}^{2}$, or $>27 \mathrm{~kg} / \mathrm{m}^{2}$ with at least one weight-related comorbidity. Phentermine is a sympathomimetic agent that induces serotonin, noradrenaline and dopamine reuptake inhibition, suppressing appetite. Topiramate causes weight loss; 4 its postulated effects include increasing energy expenditure, decreasing energy efficiency and decreasing caloric intake. In Australia, phentermine is available for use as short-term monotherapy for obesity and topiramate is available for treatment of epilepsy, migraine prophylaxis and treatment of neuropathic pain.

The efficacy of phentermine-topiramate has been assessed in Phase III trials, with a maximal weight loss of $10.9 \%$ reported for overweight and obese patients. ${ }^{5-7}$ The most frequent adverse effects were dry mouth, paraesthesia, constipation and insomnia. Recent studies have shown that phentermine monotherapy is relatively safe; it has no significant effects on blood pressure and heart rate ${ }^{8}$ and it does not induce psychological dependence or addiction. ${ }^{9}$

Phentermine-topiramate therapy is used for maintenance of weight loss in

Abstract

Objective: To investigate the safety, tolerability and efficacy of combination phentermine and topiramate therapy for maintenance of weight loss.

Design, setting and patients: Retrospective audit of patients attending the Austin Health Weight Control Clinic who were dispensed phenterminetopiramate between 22 January 2010 and 16 July 2012 and after reaching a target weight by following a very low energy diet (VLED). Data collection continued until July 2013.

Main outcome measures: Number of patients who ceased pharmacotherapy; duration of use of pharmacotherapy; types and numbers of adverse effects; and mean weight and blood pressure measurements at the initial visit, the end of the VLED and the last observation during pharmacotherapy.

Results: Data were available for 103 patients who were dispensed phenterminetopiramate; 61 patients ceased combination pharmacotherapy before the end of the data collection period, 41 due to adverse effects (eg, paraesthesia, cognitive changes, dry mouth and depression). The mean duration of use of pharmacotherapy was 10 months. Mean weight decreased by $10 \%$ due to the VLED (from $135.5 \mathrm{~kg}$ to $122.5 \mathrm{~kg}$ ) and this loss was maintained. For 30 patients who continued on phentermine-topiramate, the mean duration of pharmacotherapy was 22 months and the mean weight decreased by $6.7 \mathrm{~kg}$ between the end of the VLED and the last observation during pharmacotherapy.

Conclusion: Phentermine-topiramate therapy was not well tolerated; more than half of the patients in our study stopped taking it because of adverse effects, and more than half of the adverse events reported were ascribed to topiramate. However, in those able to continue with pharmacotherapy, the combination was efficacious for both maintenance of weight loss and ongoing weight loss.

selected adults who attend the Austin Health Weight Control Clinic, a tertiary centre obesity service. We aimed to investigate its safety, tolerability and efficacy.

\section{Methods}

Patients who attend the Austin Health Weight Control Clinic follow a ketogenic very low energy diet (VLED) to suppress hunger ${ }^{10}$ until they achieve a target weight. They then receive dietary advice on reintroduction of carbohydrates. Selected patients are also offered oral phentermine $15 \mathrm{mg}$ and topiramate $25 \mathrm{mg}$ (a non-controlled release formulation that is taken in the morning) for an indefinite period for maintenance of weight loss. Those who have active ischaemic heart disease or severe hypertension, and those who are concurrently taking antidepressants, are not offered pharmacotherapy. Women of childbearing age are counselled about the teratogenicity of topiramate, which causes cleft lip and palate in the fetus. Patients are seen monthly during the weight loss phase and at the physician's discretion during the weight maintenance phase (usually 3-monthly).

We used the Austin Hospital's pharmacy records to identify patients dispensed phentermine-topiramate between 22 January 2010 and 16 July 2012. Patient data (sex and age; weight, height and blood pressure measurements; and qualitative data regarding potential adverse effects and reasons for ceasing pharmacotherapy) were collected from the Weight Control Clinic's electronic database. Data collection continued until July 2013. Patients who did not attend the clinic for more than 6 months were defined as being lost to follow-up.

We analysed the data at four time points: Time 1, the initial visit; Time 2, the end of the VLED; Time 3, the time point during pharmacotherapy at which the nadir weight measurement was taken; Time 4, the time point during pharmacotherapy at which the 
1 Characteristics of the total cohort, reported as mean (SD)

\begin{tabular}{|c|c|c|c|}
\hline & Men $(n=38)$ & Women $(n=65)$ & Total $(n=103)$ \\
\hline Age, years & $50(14)$ & $48(13)$ & $49(13)$ \\
\hline Body mass index at Time 1, kg/m² & $49.8(12.6)$ & $47.9(9.4)$ & $48.6(10.7)$ \\
\hline Weight at Time 1, kg & $147.1(38.3)$ & $128.7(26.8)$ & $135.5(32.6)$ \\
\hline Weight at Time 2, kg & $131.4(33.0)^{\dagger}$ & $117.3(26.5)^{\dagger}$ & $122.5(29.7)^{\dagger}$ \\
\hline Weight at Time $3, \mathrm{~kg}$ & $126.1(33.6)^{\dagger \ddagger}$ & $108.4(26.4)^{\dagger \ddagger}$ & $115.1(30.4)^{\ddagger \ddagger}$ \\
\hline Weight at Time 4, kg & $128.3(34.1)^{\dagger \ddagger}$ & $111.5(25.9)^{\ddagger \ddagger}$ & $117.7(30.2)^{\ddagger \ddagger}$ \\
\hline Final weight, kg* & $130.9(37.6)^{\dagger \S}$ & $113.4(26.5)^{\dagger \ddagger}$ & $119.9(32.0)^{\dagger \ddagger}$ \\
\hline Final body mass index, $\mathrm{kg} / \mathrm{m}^{2 *}$ & $43.3(11.4)^{\text {я }}$ & $42.3(9.0)^{\text {) }}$ & $42.7(9.9)^{9}$ \\
\hline
\end{tabular}

* Weight at Time 1 was carried forward for patients who were lost to follow-up. $\dagger P<0.001$ for difference when compared to weight at Time $1 . \ddagger P=0.01$ for difference when compared to weight at Time 2. $\S P=0.79$ for difference when compared to weight at Time 2 . q $P<0.001$ for difference when compared to body mass index at Time 1 .

last weight measurement was taken. For those lost to follow-up, weight measurements at Time 1 were carried forward to calculate mean final weight and mean final BMI, an intention-totreat analysis. For those who ceased pharmacotherapy before the end of the data collection period, we analysed mean weight 3-6 months and 12-18 months after cessation, using available weight data.

Statistical analysis was performed using SPSS Statistics 20.0 (IBM). Paired $t$ tests were used to compare weight and blood pressure data between time points.

The Austin Health Research Ethics Unit approved the study as an audit activity.

\section{Results}

During the study period, 125 patients were dispensed phentermine-topiramate. Data for 103 patients were analysed as no data were available for the remainder. Patients were initially severely obese (Box 1), and the mean duration of pharmacotherapy was 10 months (median, 6 months; interquartile range, 13 months). Mean weight decreased by $13.0 \mathrm{~kg}$ due to the VLED, a 10\% decrease. Mean weights at Time 3 and Time 4 were significantly lower than mean weights at Time 1 $(P<0.001)$. Using intention-to-treat analysis, mean final weight and mean final BMI $\left(119.9 \mathrm{~kg}, 42.7 \mathrm{~kg} / \mathrm{m}^{2}\right)$ were significantly lower than mean weight at Time 1 and mean BMI at Time 1 $\left(135.5 \mathrm{~kg}, 48.6 \mathrm{~kg} / \mathrm{m}^{2}\right)$, respectively $(P<0.001)$.

Pharmacotherapy was ceased by 61 patients (41 ceased due to adverse effects ascribed to pharmacotherapy, and 20 for other reasons [eg, three started antidepressant therapy, one was planning to get pregnant and one had laparoscopic banding]), 30 patients continued pharmacotherapy, and 12 patients were lost to follow-up.

A total of 67 adverse effects were reported among 52 patients, the most frequent being paraesthesia, cognitive changes and depression (adverse effects of topiramate) and headaches, dry mouth and palpitations (adverse effects of phentermine) (Box 2). There was a significant difference in mean systolic blood pressure between Times 1 and $3(P=0.02)$ but no significant differences for mean systolic or diastolic blood pressure between other time points (Box 3).

For the 30 patients who continued on phentermine-topiramate (Box 4), mean duration of pharmacotherapy was 22 months (median, 23 months; interquartile range, 12 months); 26 patients took it for $>12$ months and 13 took it for $>24$ months. Seven of these 30 patients had adverse events: dysgeusia, dry mouth, paraesthesia, agitation, nausea and, in one patient, initial memory loss. Between Times 1 and 2, mean weight for these patients decreased by $16.0 \mathrm{~kg}$ - a $12 \%$ decrease. By Time 4, overall, the mean weight decreased by a further $6.7 \mathrm{~kg}$. However, for men, the decrease in weight between Time 2 and Time 4 was not significant. No significant changes were observed in blood pressure measurements for these patients (data not shown).

Weight data after ceasing pharmacotherapy were available for 51 patients who ceased pharmacotherapy
2 Frequency of adverse effects in the total cohort $(n=103)$ *

\begin{tabular}{lcc} 
Adverse effect & No. of patients & Likely causative drug \\
\hline Paraesthesia & 8 & Topiramate \\
Cognitive changes & 7 & Topiramate \\
Headaches & 7 & Phentermine \\
Dry mouth & 7 & Phentermine \\
Palpitations & 6 & Phentermine \\
Depression & 6 & Topiramate \\
Change in sleep & 4 & Phentermine \\
pattern & & Topiramate \\
Nausea & 4 & Topiramate \\
Dizziness & 3 & Phentermine \\
Anxiety & 3 & Topiramate \\
Dysgeusia & 3 & Topiramate \\
Drowsiness & 3 & Phentermine \\
Aggression $~$ & 1 & Phentermine or topiramate \\
behavioural change & & Phentermine or topiramate \\
Urinary frequency & 1 & Phentermine or topiramate \\
Restless legs & 1 & Phentermine or topiramate \\
Hair loss & 1 & Phentermine or topiramate \\
Constipation & 1 & \\
Skin rash & 1 &
\end{tabular}

3 Mean systolic and diastolic blood pressure for the total cohort $(n=103) *$

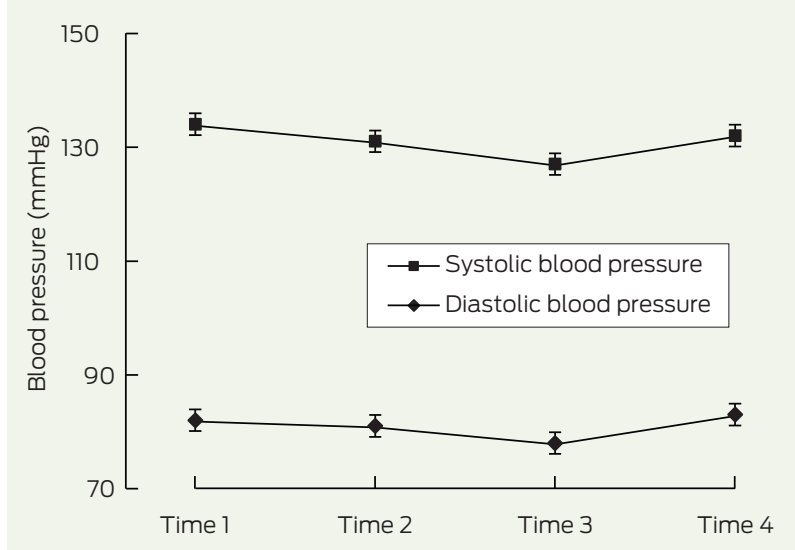

* Error bars indicate SEMs; $P=0.002$ for difference between systolic blood pressure at Time 1 and Time 3; $P>0.05$ for all other differences.

(Box 5). Between Times 1 and 2, mean weight for these patients decreased by $11.4 \mathrm{~kg}$. By the end of pharmacotherapy, the mean weight decreased by a further $3.8 \mathrm{~kg}$. At 3-6 months after cessation, mean weight had increased by $3.5 \mathrm{~kg}$ (based on data for 49 patients). By 12-18 months after cessation, mean weight increased by a further $1.0 \mathrm{~kg}$ (based on data for 28 patients). Mean weights at and after cessation of pharmacotherapy were statistically different to mean weights 


\section{Characteristics of patients who were on pharmacotherapy until the end of the data collection period,} reported as mean (SD)

\begin{tabular}{lccc} 
& Men $(n=12)$ & Women $(n=18)$ & Total $(n=30)$ \\
\hline Age, years & $52(15)$ & $52(9)$ & $52(12)$ \\
Body mass index at Time 1, kg/m² & $50.3(15.3)$ & $50.2(10.1)$ & $50.2(12.3)$ \\
Weight at Time 1, kg & $136.4(40.3)$ & $130.2(22.5)$ & $132.6(30.4)$ \\
Weight at Time 2, kg & $121.4(26.9)^{*}$ & $113.3(18.3)^{*}$ & $116.6(22.1)^{*}$ \\
Weight at Time 3, kg & $113.3(28.9)^{* \dagger}$ & $100.4(15.2)^{* \dagger}$ & $105.6(22.2)^{* \dagger}$ \\
Weight at Time 4, kg & $117.4(34.9)^{* \neq}$ & $105.0(14.5)^{* \dagger}$ & $109.9(25.0)^{* \dagger}$
\end{tabular}

$* P<0.001$ for differences when compared to weight at Time $1 . \dagger P<0.001$ for differences when compared to weight at Time 2 . $\ddagger P=0.23$ for difference when compared to weight at Time 2 .

\section{Mean weights of patients who ceased pharmacotherapy} before the end of the data collection period*

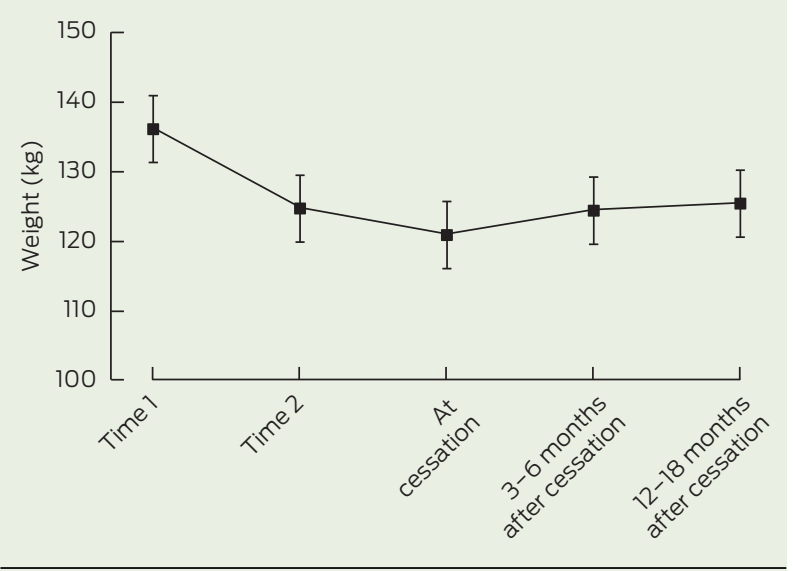

* Error bars indicate SEMs; data at Time 1, Time 2 and time of cessation represent 51 patients; data at 3-6 months after cessation represent 49 patients; data at 12-18 months after cessation represent 28 patients; $P<0.001$ for differences between weight at Time 1 and all other time points; $P=0.58$ for difference between weight at Time 2 and $3-6$ months after cessation; $P<0.001$ for difference between weight at Time 2 and at cessation; $P=0.79$ for difference between weight at Time 2 and 12-18 months after cessation. higher than the $8 \%-16 \%$ dose-related adverse effect dropouts reported for a Phase III trial of controlled-release phentermine-topiramate. ${ }^{5}$ The profile of adverse effects in our study also differs; we saw higher rates of depression, anxiety and cognitive changes. This could be due to over-reporting, as patients in our study were asked about adverse effects at each visit and most new symptoms were ascribed to phentermine and/or topiramate. The lack of a dose titration schedule and the use of a non-controlled release formulation in our study may have also contributed to the higher than expected number of adverse effects ascribed to topiramate.

Limited data were available for patients who ceased phenterminetopiramate therapy. Mean weight at 12-18 months after cessation was not significantly different to weight at the end of the VLED, but was significantly lower than the initial weight. However, this result represents only 28 patients and a short duration of follow-up.

The major limitation of this study is the lack of a control arm. The most common reasons for patients not being offered pharmacotherapy were antidepressant use and active ischaemic heart disease. This meant that the patients who were not offered pharmacotherapy were not suitable as comparators.
Combination pharmacotherapy with phentermine and topiramate may soon be available in Australia. The results of our study show low tolerability. However, for those who are able to continue phentermine-topiramate, the combination appears to be efficacious not only for maintenance of weight loss but also for ongoing weight loss.

Acknowledgements: Joseph Proietto is partly supported by the Sir Edward Dunlop Medical Research Foundation.

Competing interests: No relevant disclosures.

Received 9 Dec 2013, accepted 3 June 2014.

1 Australian Bureau of Statistics. Profiles of health, Australia, 2011-13. Canberra: ABS, 2012. (ABS Cat. No. 4338.0.) http://www.abs.gov.au/ ausstats/abs@.nsf/mf/4338.0?OpenDocument (accessed Jun 2014).

2 Korda RJ, Joshy G, Jorm LR, et al. Inequalities in bariatric surgery in Australia: findings from 49364 obese participants in a prospective cohort study. Med J Aust 2012; 197: 631-636.

3 Sumithran P, Prendergast LA, Delbridge E, et al. Long-term persistence of hormonal adaptations to weight loss. N Engl J Med 2011; 365: 1597-1604

4 Bray GA, Hollander P, Klein S, et al. A 6-month randomized, placebo-controlled, dose-ranging trial of topiramate for weight loss in obesity. Obes Res 2003; 11: 722-733.

5 Allison DB, Gadde KM, Garvey WT, et al. Controlled-release phentermine/topiramate in severely obese adults: a randomized controlled trial (EQUIP). Obesity (Silver Spring) 2012; 20: 330-342.

6 Gadde KM, Allison DB, Ryan DH, et al. Effects of low-dose, controlled-release, phentermine plus topiramate combination on weight and associated comorbidities in overweight and obese adults (CONQUER): a randomised, placebo-controlled, phase 3 trial. Lancet 2011: 377: 1341-1352.

7 Garvey WT, Ryan DH, Look M, et al. Two-year sustained weight loss and metabolic benefits with controlled-release phentermine/ topiramate in obese and overweight adults (SEQUEL): a randomized, placebo-controlled, phase 3 extension study. Am J Clin Nutr 2012; 95: 297-308.

8 Hendricks EJ, Greenway FL, Westman EC, Gupta AK. Blood pressure and heart rate effects, weight loss and maintenance during long-term phentermine pharmacotherapy for obesity. Obesity (Silver Spring) 2011; 19: 2351-2360.

9 Hendricks EJ, Srisurapanont M, Schmidt SL, et al. Addiction potential of phentermine prescribed during long-term treatment of obesity. Int J Obes (Lond) 2014; 38: 292-298.

10 Sumithran P, Prendergast LA, Delbridge E, et al. Ketosis and appetite-mediating nutrients and hormones after weight loss. Eur J Clin Nutr 2013; 67: 759-764. 